\title{
Mapa Dinâmico \& Texto Livre: uma nova abordagem de práticas educacionais
}

\author{
Bruno dos Santos Pastoriza \\ Atua na área de educação química, no Instituto de Química da UFRGS. \\ E-mail: bruno.pastoriza@ufrgs.br
}

Rochele de Quadros Loguercio

Professora do Instituto de Química da UFRGS, atua na área de educação química da UFRGS.

E-mail: cheliql@hotmail.com

\section{Resumo}

Mais recentemente, o impacto dos avanços

tecnológicos aplicados à educação contribuiu para o aprimoramento das metodologias utilizadas no ensino. Um reflexo disto reside no aperfeiçoamento dos instrumentos educacionais, trabalhados aqui como os textos e mapas conceituais, que partem em busca de um caráter mais significativo, inspirado na teoria ausubeliana, permitindo, por meio da ferramenta computacional, o aumento de sua interação e expansão a outras fronteiras como as do mundo multidimensional. Com base nestes avanços, este artigo apresenta abordagens diferenciadas, articuladas com a visão epistêmica do filósofo da ciência Gaston Bachelard às práticas educacionais tradicionais referentes ao uso de textos e mapas conceituais, principalmente quando aplicados em temas relacionados às ciências, a fim de trazer à tona mais uma possibilidade de trabalho no meio educacional.

\section{Palavras-chave}

Mapa conceitual. Ferramenta de texto. Abordagem diferenciada.

\section{Dynamic Map \& Free Text: a new approach of educational practices}

\begin{abstract}
Recently the impact of the technological progress applied to education contributed to the improvement of methodologies used on teaching. A reflex of that is based on the improvement of educational instruments, worked here as texts and conceptual maps, that seek a more significant character, inspired in the Ausubel's theory, allowing, by computational tool, the increase in interaction and expansion to other frontiers, as for instance to the multidimensional world. Thus, based on these progresses, differentiated approaches are presented according to the epistemological view of Gaston Bachelard, philosopher of science. They are applied to the traditional educational practices referring to the use of texts and conceptual maps, mainly when applied to topics related to science, so that one more possibility of work can be brought up in the educational environment.
\end{abstract}

\section{Keywords}

Conceptual map. Text tool. Differenced approach. 


\section{INTRODUÇÃO}

As ferramentas da rede internacional de computadores e as possibilidades de educação a distância de qualidade são a base da pesquisa que realizamos, e, assim, apresentamos neste artigo alguns de seus resultados e potencialidades.

Há na educação em ciências um trabalho de construção dos conhecimentos mediante a produção de mapas conceituais que facilitam, segundo alguns autores, o entendimento de teorias e projetos tanto no que diz respeito ao seu objetivo/ sistematização, quanto aos subsunçores necessários para que se possa compreendê-los. Há um conhecimento produzido na filosofia da ciência, em especial, na obra de Gaston Bachelard, que enfatiza as produções de obstáculos epistemológicos emergentes na própria explicitação/divulgação/didatização da ciência. Dessas teorias e da percepção da escassez de recursos midiáticos que contemplem as propostas produzidas em 40 anos de educação em ciências, visibilizamos as condições de emergência de nosso trabalho.

A pesquisa se realizou mediante alguns movimentos: a) a investigação de produções midiáticas via rede internacional de computadores em educação em ciências; b) a análise de estudos bachelardianos; c) a produção de um software que contemplasse aspectos fundamentais de sua teoria, procurando respeitá-los no que concerne à sua explicitação/divulgação/didatização; d) a aplicação de um piloto em sala de aula para análise dos alunos de licenciatura em química.

Neste artigo, explicitamos a construção dos resultados da pesquisa que são as ferramentas Mapa Dinâmico e Texto Livre desde sua construção em oposição às produções que já existem, que são os mapas conceituais lineares e os hipertextos. No entanto, não podemos apresentar o resultado da pesquisa sem enfatizar o seu objeto/referência, que são aspectos da obra bachelardiana.
O filósofo da ciência Gaston Bachelard (18841962) produziu extensa obra sobre o pensamento, ou melhor, o espírito científico. Dentre suas várias contribuições, destacamos a noção de obstáculos epistemológicos.

Um obstáculo epistemológico se incrusta no conhecimento não questionado. Hábitos intelectuais que foram úteis e sadios podem, com o tempo, entravar a pesquisa (BACHELARD, 1996, p. 19).

Embora sua obra global envolva aspectos relativos tanto à ciência quanto à poética, seu uso na educação em ciências está normalmente associado à identificação e crítica às figuras de linguagem que podem levar aos obstáculos epistemológicos e que se fazem presentes nas diversas formas de expressão científica, que vão desde a produção de novos conhecimentos até aos processos de ensino e divulgação, como em materiais didáticos de química/ciências e na chamada literatura de divulgação científica ${ }^{1}$.

Sob a análise de Bachelard,

o ato de conhecer dá-se contra um conhecimento anterior, destruindo conhecimentos mal estabelecidos, superando o que, no próprio espírito, é obstáculo à espiritualização (BACHELARD, 1996, p. 17).

Seus estudos, quando transladados para a educação em ciências, conduzem-nos a repensar as práticas pedagógicas que permeiam a ciência escolar. Nesse sentido, podemos perceber os efeitos e a importância de trabalhar algumas obras bachelardianas, em especial a Formação do Espirito Cientifico (BACHELARD, 1996), nos cursos de formação de professores.

$\mathrm{Na}$ formação inicial e continuada de professores, a utilização de textos em salas de aula é prática muito comum que se reproduz ao longo da história da educação. Temos também uma parcela

${ }^{1}$ Para mais informações ver Strack, Loguercio e Del Pino (2006). 
crescente de professores utilizando mapas conceituais $^{2}$ no planejamento e/ou aplicação de metodologias de ensino em sala de aula. Introduzimos o pensamento bachelardiano em duas práticas educacionais convencionais, os textos e os mapas conceituais, trazendo uma abordagem diferenciada de trabalho a elas, pois entendemos que uma das formas de ampliar o tempo para discussões conceituais pode ser com o uso de processos de aprendizagem mediados por computador (PASTORIZA et al., 2007). Buscamos de início as ferramentas já tradicionais, como o hipertexto, comuns no campo educacional. Constatamos ainda que sua metodologia usual de trabalho perde parte do significado da obra de Bachelard, que está longe de ser linear e de possuir conceitos estanques e definidos de maneira descontextualizada, como em diversos materiais já produzidos nos quais uma compilação do livro adotado em aula é utilizada via internet.

Consideramos que seria preciso transpor essas ferramentas tradicionais, compondo-se um material que fosse além delas. Como resultado, produzimos uma hipermídia, alocada no sítio de endereço http:/ /www.iq.ufrgs.br/ead/bachelard, que, utilizandose da dinamicidade e virtualidade propiciadas pela tecnologia como auxiliar no processo de aprendizagem, traz estes modelos de práticas tradicionais, os mapas conceituais e textos, que tratados sob a ótica bachelardiana recebem de nós os nomes de Mapa Dinâmico e Texto Livre, respectivamente. Esta hipermídia, por fins de aplicação, trabalha os temas referentes à necessidade de evidenciação dos riscos existentes em uma materialização da ciência como verdade e os problemas que envolvem uma dita possibilidade infinita de ver através do ciberespaço, já que esses são potenciais multiplicadores de uma visão equivocada da ciência representacional.

\footnotetext{
${ }^{2}$ Aqui adotamos a noção de mapas conceituais segundo Moreira e Rosa (1986), que os tratam do seguinte modo: "Em um sentido amplo, mapas conceituais são apenas diagramas indicando relações entre conceitos. Mais especificamente, podem ser vistos como diagramas hierárquicos que procuram refletir a organização conceitual de uma disciplina ou parte dela, ou seja, derivam sua existência da estrutura conceitual de uma área de conhecimento."
}

$\mathrm{Na}$ utilização destas ferramentas da rede para ensinar sobre o caráter representacional da ciência, é importante romper com estabelecidas hierarquias conceituais linearizadas nos mapas conceituais tradicionais sem incorrer em erros realistas de constituição de significados que higienizam, hoje, as práticas da ciência, porém essas práticas de pensar o pensamento científico só se legitimam no interior de práticas científicas. É necessário romper com a cultura linearizante de algumas práticas educacionais dentro do campo educacional, da mesma forma que, como observa Foucault (2008), Bachelard rompe com a cultura científica dentro da própria cultura científica. Aos modelos de práticas desenvolvidos demos o nome de Mapa Dinâmico e Texto Livre, que trazem em sua base a noção dos mapas conceituais e textos vigentes, respectivamente, mais utilizados no ensino, entretanto, expandindo-os.

\section{BACHELARD E SUA CONTEMPORANEIDADE}

Para a compreensão da visão epistemológica da hipermídia produzida, faz-se necessário entender Bachelard e o pensamento que desenvolveu em sua contemporaneidade.

Bachelard rompe com o estabelecido em campos distintos do saber em busca de uma filosofia das ciências que não ignora a imaginação. É assim que Bachelard impõe seu pensamento, sua epistemologia, sua Filosofia do Não, que em nada se aproxima da negação da ciência e seus objetos ou da filosofia e suas doxas, mas que problematiza e revê Kant, Descartes e Hegel ao construir o novo espírito científico que vem na rede da fala einsteiniana, onde a descontinuidade da ciência se evidencia e o mecanicismo cartesiano cede lugar ao espaço vazio das representações (LOGUERCIO, 2008).

A imaginação, cara a Bachelard, é um dos pilares da construção científica, sendo que a representação está inexoravelmente perpassada pela razão intelectualizada, bem como a construção científica 
está amparada por princípios ativos (razão e dialética) e princípios aplicados (racionalismo, métodos, pedagogia científica) (GINESTIER, 1968). Para empreender uma tecnologia educacional, como pretendemos, que pode reduzir a relação do texto intelectualizado e a construção de representações pelos alunos, é necessário considerar as possibilidades de não realizar o objeto de estudo em prol de sua pedagogia e definir o entendimento de representação.

O plano da representação devidamente intelectualizado é o plano em que trabalha o pensamento científico contemporâneo; o mundo dos fenômenos científicos e a nossa representação intelectualizada. Vivemos no mundo da representação schopenhaueriana. Pensamos no mundo da representação intelectualizada. $\mathrm{O}$ mundo em que se pensa não é o mundo em que se vive.

A Filosofia do Não constituir-se-ia em doutrina generalizada se conseguisse coordenar todos os exemplos em que o pensamento rompe com as obrigações da vida (BACHELARD, 1999, p. 67).

É preciso romper com a noção ocularista e intelectualizada, primazia de determinada corrente filosófica (SIMÕES, 2008) e perceber a não possibilidade de aproximação gradual e quimérica com a verdade da natureza; é preciso mudar de ciência e entender que não existe realidade, ela é sistematicamente inventada em um universo representacional. Como destaca Heinsenberg (apud ARENDT, 1972), não há nada que não seja o homem em diferentes disfarces. Bachelard usa o próprio empirismo como forma de explicação do que ele chama de nova experiência, nova lógica, pois a ciência atual trabalha com o microuniverso, o que vai além dos sentidos e se apoia em máquinas de ver, que são criadas e que criam, portanto. "A ciência instrumentada é a transcendência da ciência de observação natural. Há uma rotura entre conhecimento sensível e conhecimento científico" (BACHELARD, 1999, p. 7).
Buscando trazer as problematizações de Bachelard sobre a representação e a materialidade de um universo construído longe da imagem, perguntamos: como fica a educação em química/ ciências na era do ciberespaço? Onde transitam os espaços de representação? Como proporcionar para $\mathrm{o}$ aluno um lugar criativo?

Para Weizenbaum (apud MORAES, 2000),

o computador é uma nova e poderosa metáfora que nos ajuda a compreender muitos aspectos do mundo, mas subjuga o espírito que não é capaz de recorrer a outras metáforas e outros recursos". O recurso da imaginação é para Bachelard imperativo na ciência, e entendemos que também é fundamental na educação em ciências. Por essa razão, é fato a necessidade de exercitar a crítica ao mundo visível, aos processos da linguagem, às práticas pedagógicas. Nesse sentido, é preciso conhecer Bachelard e seu entendimento da ciência, bem como situar esse olhar crítico sobre materiais didáticos ou midiáticos que participam da construção de nossa representação de ciências e, em particular, da química.

Destacamos da hipermídia alguns dos conceitos de Bachelard que têm aplicações imediatas nas leituras dos materiais didáticos usados em práticas pedagógicas, mais especificamente de química, como os obstáculos epistemológicos, mas também privilegiamos conceitos de entendimento mais amplo, como a fenomenotécnica e o surracionalismo.

\section{A FERRAMENTA DE HIPERMÍDIA E AS POSSIBILIDADES DIDÁTICAS}

A ferramenta de hipermídia - termo que surge em seguida ao termo hipertexto e expande sua noção de apresentação de conceitos, não os tendo mais apenas como textos contendo links, mas sim como textos integrados com imagens, sons, animações, jogos (PONTUSCHKA, 2006) - permite o desenvolvimento de novas formas de interação e monitoramento do usuário com o material ao qual é apresentado. 
Os sítios da rede internacional de computadores em sua maioria apresentam as ferramentas hipertexto e hipermídia contendo vários conceitos marcados e destacados em cores diferentes se remetendo a maiores informações sobre os mesmos. Entendemos que essa forma de apresentação, ainda que interessante e válida, incorre no mesmo erro das caixas de textos presentes nos livros didáticos, configurando recursos que não permitem o exercício de "reconhecer" os principais conceitos e ideiaschaves do texto, mas sim que levam a crer que eles o são, pois se tem na marcação dos conceitos um direcionamento do olhar (LOGUERCIO; SAMRSLA; DEL PINO, 2001).

Desta forma, torna-se irrelevante a mídia utilizada para trabalhar os conceitos e sua materialidade, se permanecemos enunciando os mesmos discursos tradicionais, dentre eles, que existem coisas e fatos mais importantes e outros menos, que a ciência já estabeleceu, e que basta ao aluno uma leitura direcionada para a apropriação desses conhecimentos. É inegável que se aprende também dessa maneira, com essas marcações, no entanto, se partirmos de nosso entendimento da obra de Bachelard e entendermos o caráter representacional, temos de admitir que em cada episteme as representações são feitas de formas diferentes e que a cultura dos indivíduos é responsável por aquilo que eles entenderão como conceito fundamental e definirá o que eles irão perceber como ideias-chave em um autor.

Por essa razão, o texto que abre uma das duas possibilidades de navegação no sítio traz um texto que aborda de forma introdutória a produção de Gaston Bachelard, entretanto evita as marcações e destaques coloridos que caracterizam o biperlink, que faz a relação com outras páginas, buscando a liberdade de escolha e os trajetos próprios de cada leitor (figura 1). A diferença entre o hipertexto e o material que construímos é pequena, sutil, mas fundamental, pois ela tenta romper com o estabelecido livro digital e suas caixas de textos midiatizadas em prol de uma leitura errática, caótica e livre, dando àquele que utiliza a hipermídia o papel ativo na construção dos conceitos.

\section{FIGURA 1}

\section{Tela de apresentação do formato Texto Livre}

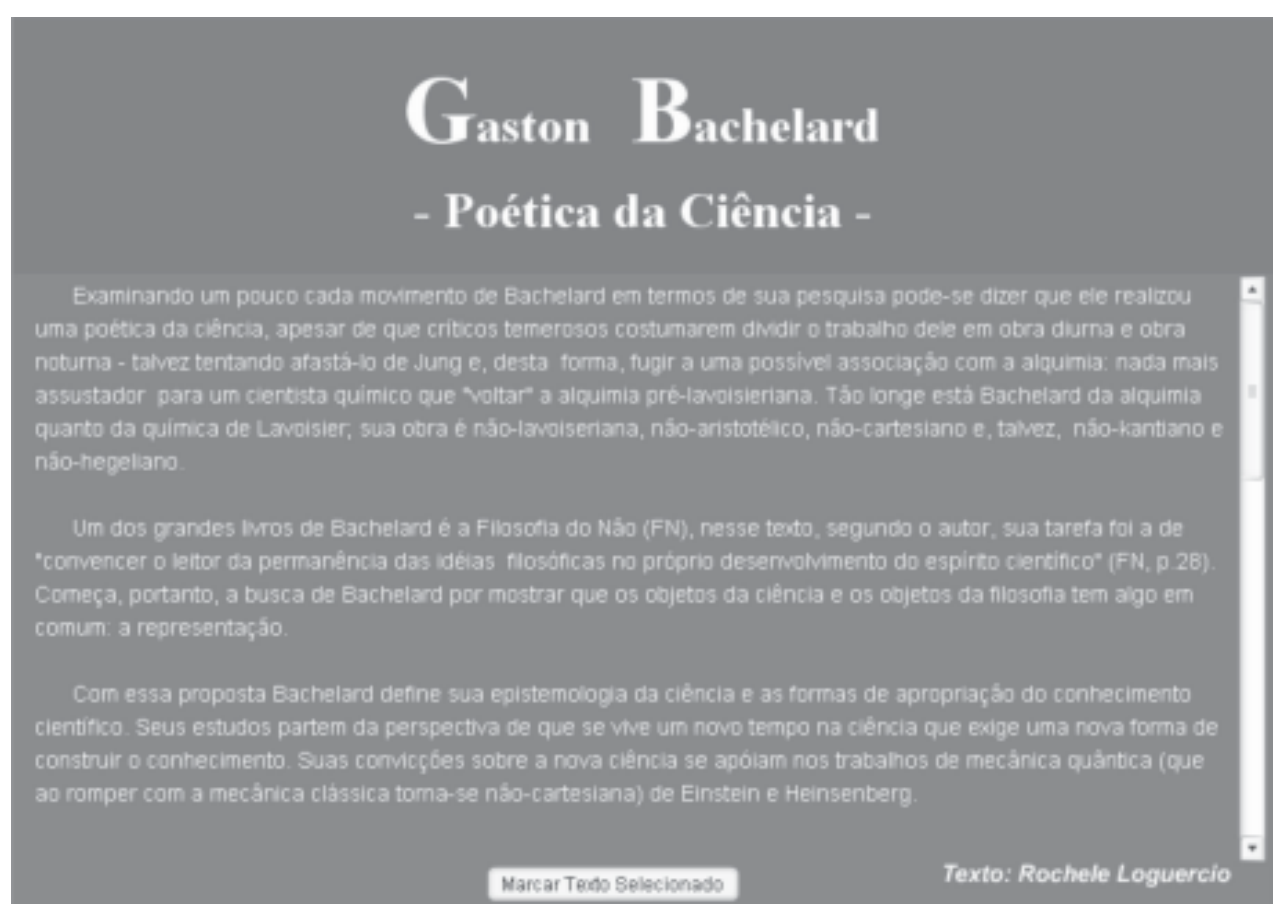


Para esta possibilidade de navegação surgem alguns questionamentos a respeito de como ela se constitui: remete a outros textos e outras páginas? Usa os recursos de enfatizar conceitos? Qual a ferramenta utilizada? Neste modo de navegação, é o usuário quem enfatiza os conceitos, residindo aí a diferença entre nosso material e o hipertexto comum. Caso a ênfase realizada pelo usuário seja considerada por nós um ponto importante da obra de Bachelard, ele é levado a outras páginas que expandem os conceitos destacados. Caso contrário, ele é levado a uma área em que lhe é possibilitada a alternativa de fazer questionamentos ou explicar aos administradores do sítio o porquê da marcação realizada. Destaca-mos que as formas usualmente conhecidas como links são trabalhadas em uma nova perspectiva; as marcações dos conceitos estão sumidas, escondidas como tramas de um tecido que o leitor constrói, sendo as ferramentas desta construção a percepção, uma caneta marca texto virtual e um universo de possibilidades. Por meio desta abordagem, temos possibilidade de argumentação com aquele que utiliza a hipermídia, estreitando a ligação entre a parte que desenvolve a ferramenta e aquela que a utiliza, constituindose assim mais um espaço de discussão no campo da educação.

Da mesma forma que o texto, a outra possibilidade de navegação é um instrumento já tradicionalmente utilizado em práticas educacionais: os mapas conceituais, propostos por Novak e Gowin (1984), que foram desenvolvidos como forma de instrumentalizar a teoria de aprendizagem significativa de Ausubel (RUIZ-MORENO et al., 2007). Como relatado por Moreira e Rosa (1986, p. 17, inserção nossa),

os [mapas conceituais] tridimensionais, embora ofereçam grandes possibilidades de representação de estruturas conceituais, ficam difíceis de traçar.

Conseguimos, entretanto, transpor essa dificuldade. $\mathrm{Na}$ hipermídia desenvolvida, o mapa conceitual construído faz uma representação em três dimensões dos conceitos abordados e, indo além dessa característica, recebe um caráter dinâmico, possibilitando a manipulação e movimentação espacial desses conceitos por parte daquele que o utiliza, conforme é possível visualizar na figura 2 . Este material busca nas ferramentas tecnológicas da rede, como as plataformas Flash e de desenvolvimento de páginas da web, a ruptura com os processos vigentes; traz um caráter risomático à navegação, tendo os signos dispersos, soltos em meio ao caos do pensamento, tendo o usuário a função de tecer as relações entre eles. Tal abordagem mais uma vez busca contemplar as ideias de Bachelard, ao não linearizar a informação (característica dos mapas conceituais e dos textos didáticos) e permitir a imaginação na busca dos conceitos e suas inter-relações. Mediante manipulação da ferramenta e seu giro espacial, temos uma não hierarquização de conceitos, evidenciando-se que um conhecimento não tem supremacia sobre outro, mas que é relativo aos demais.

No material produzido, os dois formatos de navegação são denominados, segundo o método

\section{FIGURA 2}

Tela de apresentação do formato Mapa

\section{Dinâmico}

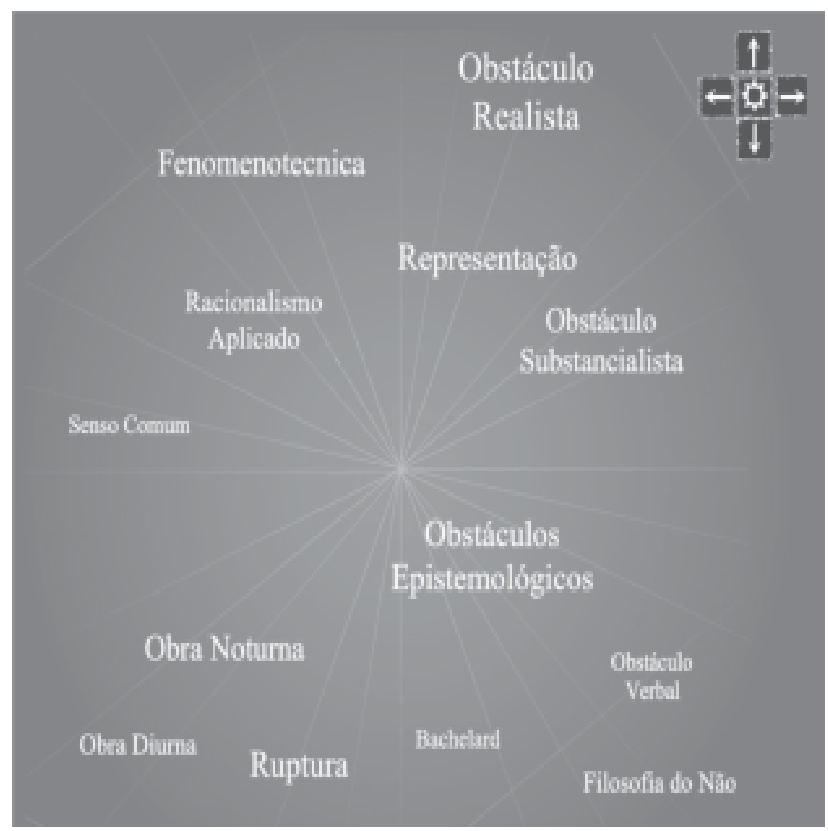


de exploração que sugerem, Texto Livre e Mapa Dinâmico, respectivamente, e, mediante estas modificações, possibilitam uma abordagem diferenciada ao método de navegação convencional, porquanto o usuário não é direcionado àquilo que deve saber, ou o que é previamente julgado interessante, mas sim pela sua própria capacidade de interpretação e de resolver o que lhe é importante.

$\mathrm{Na}$ figura 3, há uma forma de representação dos temas trabalhados através da hipermídia e que abrangem uma parte da obra de Gaston Bachelard, possibilitando a primeira imersão em seus conceitos e a introdução à discussão referente tanto aos materiais didáticos quanto à relação dos riscos de se materializar a ciência por meio de "verdades" e os problemas que giram entorno das possibilidades infinitas de "ver", seja através deles ou do ciberespaço. Após selecionados em alguma das formas de navegação, os temas são apresentados principalmente sob a forma de hipertexto, auxiliado por imagens e links, que os expandem e permitem sua articulação com outras fontes conceituais existentes na rede.

Não obstante, utilizamos arquivos de log (BARAB; BOWDISH; LAWLESS, 1997) a fim de observar os processos de navegação do usuário, apoiandonos na tendência convencional das pesquisas sobre usuário-navegação no uso de dados que registram a sequência de tópicos visitados por um leitor (caminho informacional) em um hipertexto - neste caso, na hipermídia - e que frequentemente incluem as medidas do tempo relacionado às visitas (McENEANEY, 2001).

\section{DISCUSSÃO E PERSPECTIVAS SOBRE A HIPERMÍDIA}

As ferramentas desenvolvidas estão sendo utilizadas com alunos do Curso de Licenciatura em Química da Universidade Federal do Rio Grande do Sul, buscando evidenciar a construção dos conceitos propostos na hipermídia. Embora os dados ainda não tenham sido exaustivamente analisados, podemos perceber que, assim como proposto, a leitura e a construção que cada um desenvolve a partir dos textos/signos trabalhados podem não configurar aquela melhor possível, mas trazem à tona o processo particular de cada indivíduo em sua aprendizagem, desde a sua escolha por um ou por ambos os métodos de navegação, até o desenvolvimento de uma navegação específica, tendo, mediante a articulação entre as partes integrantes deste processo (que

\section{FIGURA 3}

Possível forma de representação dos temas selecionados para serem trabalhados pela hipermídia

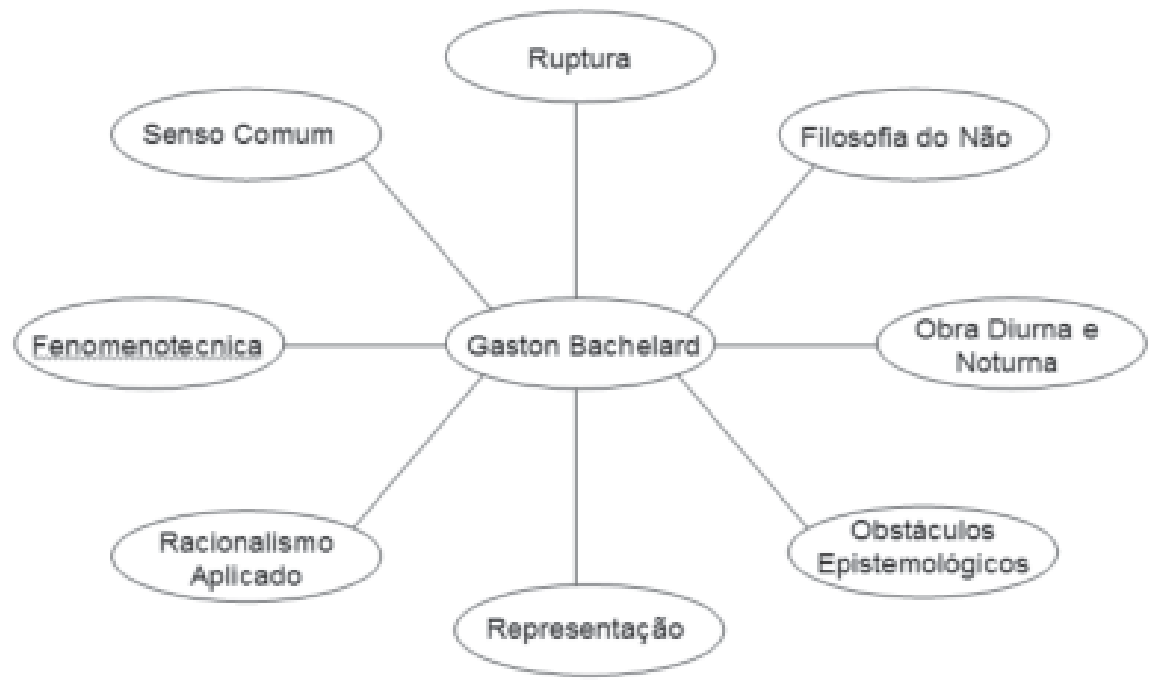


podem ser entes diversos da relação professor/ aluno), a criação da possibilidade de construção conjunta de uma aprendizagem, que, mesmo sendo em parte direcionada, vai além de uma aprendizagem mecanicista.

Ao olhar para a relação didática e os conceitos bachelardianos utilizados, podemos considerar que o instrumento não os contrapõe, uma de nossas maiores preocupações, outrossim, que os respeita em função de sua dinamicidade e da interação com outros sítios que abordam o pensamento de Bachelard em diferentes perspectivas.

É sob estas noções de inter-relações conceituais, construções próprias de cada aluno, virtualidade e dinamicidade que a ferramenta propõe que, assim como no emprego de qualquer nova ferramenta, uma das principais preocupações pode residir: o processo de avaliação. Assim, na hipermídia desenvolvida, é possível que a utilização conjunta de diversos instrumentos seja um diferencial neste processo, agrupando, por exemplo, os dados colhidos dos arquivos de $\log$ a formulários de concepções prévias e/ou posteriores, sendo expansível até mesmo a discussões em grupo.

Como citado, o objeto já pode ser encontrado na rede no endereço http://www.iq.ufrgs.br/ead/ bachelard e pode ser utilizado como aproximação de alguns conceitos do autor, salientando-se que ainda se encontra em construção, visto que existe vasto material relacionado à obra bachelardiana que poderá ser incorporado, inclusive aqueles disponíveis em outras mídias, qualificando ainda mais o propósito do trabalho em constituir uma hipermídia que aborde os conceitos do autor.

\section{AGRADECIMENTOS}

À Secretaria de Educação a Distância (Sead/ UFRGS), pelo financiamento da bolsa de pesquisa.

Artigo submetido em 02/10/2008 e aceito em 14/05/2009.

\section{REFERÊNCIAS}

ARENDT, H. A conquista do espaço e a estatura humana. In: ALMEIDA, Mauro W. B. Entre o passado e o futuro. 2. ed. São Paulo: Perspectiva, 1972.

BACHELARD, G. A formação do novo espirito científico: contribuição para uma psicanálise do conhecimento. Rio de Janeiro: Contraponto, 1999.

A formação do espírito científico. Rio de Janeiro: Contraponto, 1996.

BARAB, S. A.; BAWDISH, B. R.; LAWLESS, K. A. Hypermedia navigation: profiles of hypermedia users. Educational Technology Research and Development, v. 45, n. 3, p. 23-41, 1997.

FOUCAULT, M. Foucault parle de Bachelard. Disponível em: < http:/ /www.ina.fr>. Acesso em: 01 out. 2008.

GINESTIER, P. Pour connaître le penseé de Bachelard. Paris: Bordas, 1968.

LOGUERCIO, R. Ensaio sobre o pensamento bachelardiano. Revista educação e Filosofia, Uberlândia, v. 22, n. 44, 2008. No prelo.

LOGUERCIO, R. Q.; SAMRSLA, V. E. E.; DEL PINO, J. C. A dinâmica de analisar livros didáticos com professores de química. Química Nova, São Paulo, v. 24, n. 4, p. 557-562, 2001.

MCENEANEY, J. E. Graphic and numerical methods to assess navigation in hypertext. International Journal of Human-Computer Studies, v. 55, p. 761-786, 2001.

MORAES, R. A. Uma filosofia da educação para a universidade virtual. Revista On-line de Educação a Distância Conect@, n. 3, nov. 2000. Disponível em: <http://www.revistaconecta.com/ conectados/rachel_uma_filosofia.htm>. Acesso em: 30 ago. 2008.

MOREIRA, M. A.; ROSA, P. R. S. Mapas conceituais. Caderno Catarinense de Ensino de Física, Florianópolis, v. 3, n. 1, p. 17-25, 1986.

NOVAK, J. D.; GOWIN, D. B. Learning how to learn. New York and Cambridge, UK: Cambridge University Press, 1984.

PASTORIZA, B. et al. Um objeto de aprendizagem para o ensino de química geral. Revista Novas Tecnologias da Educação, Porto Alegre, v. 5, n. 2, 2007. Disponível em: < http://www.cinted.ufrgs.br/ renote>. Acesso em: 02 set. 2008.

PONTUSCHKA, M. N. Hipermídia: uma área da ciência da computação que conquistou seu espaço em proporção mundial através da internet. Revista Eletrônica Letra Magna, Ano 3, n. 4, 2006. Disponível em: <http://www.letramagna.com>. Acesso em: 03 set. 2008 .

RUIZ-MORENO, L. et al. Mapa conceitual: ensaiando critérios de análise. Ciência e Educação, Bauru, v. 13, set. 2007.

SIMÕES, R. L. M. A imaginação material segundo Gaston Bachelard. 1999. Dissertação (Mestrado em Filosofia)- Universidade do Estado do Rio de Janeiro, Rio de Janeiro, 1999.

STRACK, R.; LOGUERCIO, R. Q.; DEL PINO, J. C. A literatura de divulgação científica como recurso didático na compreensão da estrutura da matéria. In: ENCONTRO NACIONAL DE ENSINO DE QUÍMICA, 13., 2006, Campinas, SP. Anais... Campinas, SP: [s.n.], 2006. 